\title{
On the notion of causality in medicine: addressing Austin Bradford Hill and John L. Mackie
}

\author{
Sobre a noção de causalidade na medicina: aproximando Austin Bradford Hill e John L. Mackie
}

\author{
luís Fernando S. C. de Araújo', Paulo Dalgalarrondo ${ }^{1}$, Cláudio E. M. Banzato ${ }^{1}$ \\ ${ }^{1}$ Departamento de Psicologia Médica e Psiquiatria, Faculdade de Ciências Médicas, Universidade Estadual de Campinas (FCM/Unicamp), Brazil.
}

Received: 10/23/2014 - Accepted: 5/12/2014

DOI: 10.1590/0101-60830000000010

\begin{abstract}
Almost 50 years ago appeared the seminal article by Austin Bradford Hill where he presented parameters for inferring causes from statistical associations, which became known as Hill's causal criteria. This was a milestone for the renewal of the idea of cause in medicine. Our article revisits his contribution in light of the ideas from the Australian philosopher John L. Mackie, whose important works on causality reached an audience distinct from Hill's. We suggest that both the British epidemiologist and the Australian philosopher share the purpose of articulating probabilistic determinism and multi-causality, the first with a predominantly probabilistic model and the second with an analytical approach. This article explores the possible consequences of addressing these authors jointly in regard to causal inferences in medicine, especially in respect to mental disorders.
\end{abstract}

Araújo LFSC, et al. / Rev Psiq Clín. 2014;41(2):56-61

Keywords: Causality, mental disorders, schizophrenia, Alzheimer's disease.

\section{Resumo}

Há quase 50 anos era publicado o artigo seminal de Austin Bradford Hill, no qual ele apresenta parâmetros para inferência de causas com base em associações estatísticas, que ficaram conhecidas como critérios causais de Hill. Aquele foi um marco para a renovação da ideia de causa na medicina. Nosso trabalho revisita suas ideias, articulando-as com o trabalho do filósofo australiano John L. Mackie, também autor de importante obra sobre causalidade, mas que teve uma audiência distinta da que Hill alcançou. Sugerimos que tanto o epidemiologista britânico quanto o filósofo australiano têm em comum o fato de que ambos procuram articular determinismo probabilístico e multicausalidade, o primeiro com um modelo predominantemente probabilista e o segundo com uma abordagem analítica. Este artigo explora as possíveis consequências da aproximação desses dois autores no que diz respeito a inferências causais na medicina, com foco particular nos transtornos mentais.

Araújo LFSC, et al. / Rev Psiq Clin. 2014;41(2):56-61

Palavras-chave: Causalidade, transtornos mentais, esquizofrenia, doença de Alzheimer.

\section{Introduction}

The seminal article by Bradford Hill, "The Environment and Disease: Association or Causation?", was published nearly 50 years ago. Its publication was a milestone for current understanding of causality in medicine, surpassing the influential view of Robert Koch (Table 1) and permanently introducing indeterministic (or probabilistic) relations in medicine, particularly for the analysis of chronic diseases ${ }^{1-3}$.

Table 1. Koch's postulates (Susser, 1991)

\begin{tabular}{|l|}
\hline 1. The micro-organism must always be found with the disease \\
\hline 2. The germ must be isolated in culture \\
\hline 3. The germ should be distributed according to the lesions \\
\hline
\end{tabular}

The work followed research by Bradford Hill and his colleague Richard Doll on the medical consequences of smoking. In the first half of the twentieth century, there was little consensus as to whether smoking produced adverse effects on health. But the increase in cases of lung cancer in both England and the United States led to major efforts to determine the source of that epidemic. Motivated by the interest to establish the etiology of those cancers, Bradford Hill and Doll started an investigation ${ }^{4}$ that confirmed the association of smoking not only with lung cancer but also with other diseases such as acute myocardial infarction, hypertension, emphysema and chronic bronchitis.

In 1965 Bradford Hill published "The Environment and Disea$\mathrm{se}^{\text {"3, }}$, which became one of the most cited articles in the history of the health sciences. This showed that the scientific community at the time was in need of standards for the interpretation of statistical findings, thus reducing confusion about what is and what is not causal in medicine. His goal in that article was to determine which characteristics of the statistical association worked as reliable indicators for claiming that the data generated by statistical means actually represented a putative underlying causal relationship. In the article, he supplied answers to two important questions, one was explicit in his work and another tacit, but equally relevant.

He explicitly addressed a practical issue. Recognizing that cause is a disputed concept and that it varies accordingly to the epistemological framework, he wondered how much statistical information was needed before a certain relation may be considered as a causal one. Should we give a verdict of causation for certain relationships before we move to action? In the article, he mentions his concern for occupational diseases identified at the time, asking what evidence would be necessary before taking action with respect to the factors supposedly causing those diseases. For Bradford Hill it is not necessary to know all the links in the chain of causation, associations (since they were demonstrated within certain parameters) could and should be used as triggers for medical intervention or action. The 
main question then becomes what properties of an association are indicative of causality? With that question in mind he drew up a list of parameters that suggested underlying causality. This list came to be known as the Bradford Hill causal criteria (Table 2).

Implicitly his article also gave an answer to another problem: how to articulate the postulates of R. $\operatorname{Koch}^{5}$ (Table 1) in light of recent developments in medical statistics. In Koch's model, the relationship between cause and effect was given in purely deterministic terms, in the sense that one germ would be responsible for one disease. This stance failed to hold in the face of chronic diseases, whose determinants are likely to be multiple and complex. Bradford Hill, however, did not intend to completely abandon the possibility that in some circumstances there may be deterministic relationships in medicine. His proposal to include probabilistic relationships in the causal equation allows for the accommodation of relationships in the model of Koch's postulates, but also covers biological events that behave in an indeterministic way.

By accommodating both positions on determination in medicine, Bradford Hill's ideas received great recognition. He addressed, at least implicitly, a philosophical problem reinvigorated at the beginning of the 20th century with quantum physics: how to reconcile a world in which certain phenomena behave deterministically with others that seem not to behave in that way?

Bradford Hill, however, stated that that was not a philosophical work. He modestly admitted he had no desire or ability to embark on a philosophical discussion on the meaning of "causation" 3 . And indeed, philosophers and physicians have different approaches: while the latter are concerned with the practical issues related to interventions and decision-making by public health authorities, the former are concerned with issues such as our relationship with reality, the possibility of knowledge and rigorous conceptual analysis.

One particular author, little known in the medical community, perhaps a little more read amongst statisticians, made an effort to try to approximate the scientific idea of cause to the everyday one. John L. Mackie, an Australian philosopher who lived in England, proposed that causes always include diverse elements that play a role in producing the effect. Thus, when we say that A causes $\mathrm{E}$, we are almost always saying that A along with positive elements $(\mathrm{X})$ or negative (Y) is producing the effect E. Causes almost always imply a conjunction of causal elements, both with positive and negative valences for the production of a given effect ${ }^{6,7}$.

We suggest that Bradford Hill and John L. Mackie have something in common: they both seek to articulate probabilistic determinism and multi-causality. The first, with a mixed model, mostly probabilistic, and the second with an analytical, logical approach. This article focuses precisely on the possible consequences of the approach of these two authors in the treatment of causal investigations of mental disorders.

The last century, considered by some as the century of chronic diseases, witnessed an increasing interest from both the scientific community and the lay public in areas such as psychiatry, occu- pational/environmental health, and in complex conditions such as obesity, diet, use of substances, lifestyle and disease. However, despite the advances made in many related areas, the discovery of the causes of mental disorders (and analogous complex conditions) became a considerable scientific challenge. Perhaps the idea of strong causes (that is, causes with great capacity of producing the effects alone) is a bit misleading. After all, most of the chronic diseases we deal with on a daily basis most likely are produced by a myriad of causal factors operating together. Everything suggests that this is also the case with mental disorders. We will take schizophrenia as an example and make a brief analysis of the contributions of the two authors mentioned, trying to show how an analytical approach can contribute to the discussion of causality.

\section{Origins of causal thinking in Hill and Mackie}

The founder of the modern philosophy of causality was the philosopher David Hume who stated that cause is an event that is followed by another one (the effect), and that if the first had not happened the second would not occur ${ }^{8}$. This way of understanding causes is typically called regularism. Both Bradford Hill and John L. Mackie are regularists, although the former was also concerned with the material relationship that can occur between two events, hence using a Newtonian framework. For Newton, cause was defined as a relationship between two objects, and that among them was operating something he called force, as when one billiard ball causes the displacement of a second ball ${ }^{8,9}$.

Bradford Hill aimed at accounting both for the material relations that could exist in some biological processes, and for the indeterminacy that occurs in others. On the one hand, he wanted to provide an account of, for example, causality underlying the material relationship that exists between asbestos and lung injury, linked by the inflammation the former produces on the pulmonary tissue. On the other, he wanted to address causality in incomplete relations, such as when a subject is exposed to tobacco and develops lung cancer. The term incomplete here means that not every smoker develops cancer, but there is an association which is grounded on a statistical dependence between the two variables (tobacco and cancer).

According to Thygesen et al. Hill's proposal is tributary of two philosophical traditions: properties such as strength, specificity, consistency, biological gradient and experimentation belong to the regularist lineage founded by David Hume, while consistency, plausibility and analogy come from the material tradition since Aristotle, through Newton, and reaching Robert Koch ${ }^{2}$. In other words, Bradford Hill was not as radical as, for example, E. Mayr who claimed that indeterministic relationships are necessarily present in all biological events ${ }^{10}$, and accepted diverse ideas of causality, including the one from classical (Newtonian) physics. This causality of classical physics underlies the idea that the epidemiological finding must cohere with the knowledge at the time of the findings, as well be plausible - taking one hypothesis of how things happens

Table 2. Characteristics that suggest likely causal relations, according to Bradford Hill ${ }^{18}$

\begin{tabular}{|l|l|}
\hline Strength & $\begin{array}{l}\text { The stronger the association, the farther from zero will be the measure the effect studied. The idea here is to consider that } \\
\text { strong associations are more likely to be causal }\end{array}$ \\
\hline Consistency & By repeating the findings in different populations, similar outcomes are found \\
\hline Specificity & $\begin{array}{l}\text { The presence of the cause is necessary for the effect to happen } \\
\text { Some authors declare that this item is not required in the cases of diseases known to have a multi-etiological character }\end{array}$ \\
\hline Temporality & The effect should always be temporally posterior to the cause \\
\hline Biological gradient & When dose-response phenomenon happens. Thus, by increasing the (hypothetical) cause there is increased effect \\
\hline Plausibility & $\begin{array}{l}\text { If the relationship that is being studied is plausible on existing biological knowledge, there is more chance that the observed } \\
\text { relationship is causal }\end{array}$ \\
\hline Consistency & The causal interpretation must not conflict with the knowledge at the time of the investigation \\
\hline Experiment & Causal relationships are best demonstrated by experimental evidence \\
\hline Analogy & $\begin{array}{l}\text { As in the example: if we know other viral infections cause disease in childhood, by analogy we can suppose the same happens } \\
\text { with rubella. This analogy raises the chance that the observed association is causal }\end{array}$ \\
\hline
\end{tabular}


-, and that there is a possible analogy with events already reported in medicine. Hence, coherence and plausibility ultimately rely on the previous conception of a pathway (pathophysiology) that links cause to its effect, i.e., the same as the visual metaphor of the gears in the watch or the billiards balls.

\section{Complementing Hill's theory}

Hill was concerned with the more practical implications of the process of causal inference. Even though he acknowledged that the discussion of associations implies that one may not know about some of the causal links, he did not develop this aspect of his theory. The question "what is the role of the unknown elements on causal thinking in medicine?" remained unaddressed by him, but was it taken up by other authors.

Even though John L. Mackie did not mean to target medical audiences with his work, it is safe to say that he put forward a theory that is somehow related to and complements Hill's ideas. The difference, in his case, was that John L. Mackie emphasized weak causal influences and also explored negative and still unknown causal links.

John L. Mackie develops a view in which all ingredients of causation (the putative ones as well as the yet unknown) are taken into consideration. In order to do that he develops the concept of an INUS condition (from the acronym: Insufficient but Necessary part of a condition which is itself Unnecessary but Sufficient to the effect). He uses the example of a fire caused by a short-circuit, to argue that the short-circuit is not in itself sufficient nor necessary for the fire. It was not necessary because it could have happened elsewhere, or have been caused intentionally; it was not sufficient because in the absence of oxygen or in the presence of an efficient sprinkler the effect would not happen ${ }^{11}$. To speak of cause we must consider the possibility that we do not know all of its relevant components. Therefore causes are a set of things that by themselves are neither necessary nor sufficient for the effect. There is a sense of necessity, but this occurs only in a certain context or situation. When one of the components is necessary to the whole set of sufficient elements, then we are facing an INUS condition. The approach that John L. Mackie uses is analytic and it represents an INUS condition as follows:

(i) Causal element $\mathrm{A} \rightarrow$ effect $\mathrm{E}$

(ii) Causal element $\mathrm{A}+$ unknown causal elements $\mathrm{X} \rightarrow$ effect $\mathrm{E}$

or

(iii) Causal element $\mathrm{A}+$ (unknown causal elements $\mathrm{X}$ or anticausal elements $\mathrm{Y}) \rightarrow$ E effect

The condition (i) refers to causal relationships of the type envisaged by Koch: $\mathrm{A}$ is the only factor responsible for the effect $\mathrm{E}$ (in this case we say that A is necessary for E, but in most cases this is not how things happen); in (ii) it is admitted that $\mathrm{A}$ is dependent on unknown causal elements $\mathrm{X}$ and (iii) seems to better represent how things happens in the world when we do not know all the participating elements of the causal relation and suppose that some of them (Y) compete against the effect ${ }^{7}$.

\section{The hard problem of association and causality}

One of the items on Hill's agenda was to discuss how much evidence (in this case, analyzed statistical data) is necessary for medical action. He initially tries to find the parameters that define a "good" association, i.e., those associations that are likely to represent an underlying causation. But he ends his article by suggesting that we cannot depend on the verdict of causation for the passage to the intervention. Again, although not intended to be philosophical, his work touches one important philosophical question in the field of metaphysics. Can we say that associations are causes?

Associations may undergo changes according to how different explanatory levels are statistically analyzed. For example, associations can change its directionality depending if we are analyzing populations, subpopulations, individuals or intra-individual changes over time ${ }^{12,13}$. Taking an example from philosopher Nancy Cartwright, we usually accept that the frequency of heart disease increases with smoking and decreases with physical activity. Thus, in a population of sedentary smokers we would find a tendency of increasing heart disease rates. But if we come across a subset of that same sample in which all individual exercise regularly in such a way that the effect of smoking is undermined, then we can have that the association between smoking and cancer does not appear in that particular subpopulation. We are not simply pointing to the problem posed by confounding variables, which can be tackled by multivariate analysis, but to a specific feature of aggregated data in which a pattern of statistical relation can be undermined or completely change directionality depending on the explanatory level under analysis. This is a known characteristic of aggregated data, which could lead to incorrect interpretation. To paraphrase Nancy Cartwright, any association between two variables in a given population can be reversed in a subpopulation if we find a third variable that is correlated with both initial variables. To this phenomenon is given the name of Simpson's paradox and the basis in which Cartwright draws the distinction between causal laws and laws of association, allowing her to claim that the former cannot be reduced to the latter ${ }^{14}$.

One way to solve this issue appears in Mackie's project. He proposed that when we talk about causation we are indeed considering some kind of necessity. For Hume, necessity was a psychological property (habit), i.e., when we see an event, our minds already lead us to expect its effect. Mackie thought, instead, that necessity appeared in a relation to the surrounding events (and it was not a psychological property such as habit), he called it necessity-in-the-circumstances, which he considered to be the distinctive element of causation.

Mackie also claimed, quoting Bertrand Russell, that when we talk about causes we tend to overvalue the active components, at the expenses of the passive ones. For example, if John caused the fire by throwing his cigarette on the hay, we usually do not consider the presence of oxygen as a cause. However without oxygen or hay, there is no space for a discussion about causes. The idea of an INUS condition tries to address this property by stating that negative or passive elements are part of the causal complex and should be taken into consideration. For that, he engages in an analysis of sufficiency and necessity. Therefore, for example, John's cigarette is a necessary element for a sufficient conjunction of things, such as hay and the presence of oxygen, the absence of rain, etc. ${ }^{7,15}$. The cigarette thrown for him is therefore an INUS condition: an insufficient but necessary ingredient of an unnecessary but sufficient causal set.

The stance one takes in this discussion can lead to different and relevant practical consequences: Bradford Hill emphasized in his article that the description of an association is sufficient to trigger medical intervention. Remember that he was more concerned with pneumoconiosis and lung cancer, strongly related to exposure to certain dusts or fibers and tobacco, respectively. However, the use of statistical correlations in support of preventive measures has always been a controversial idea. There is a recent discussion resulting from the perception that early identification of certain types of cancer did not decrease the number of people in advanced stages of disease or mortality ${ }^{16}$. Therefore, the existence of correlation does not always ensure that a preventive measure at the level of an entire population will be sufficient.

\section{Complex causal networks}

Moreover, speaking of association has little explanatory power on the phenomenon under investigation. Any items in the field can be taken as causal variables to be compared. On the other hand Mackie's idea (INUS) allow for some explanations in terms of causal analysis. To use an example taken from the epidemiologist Kenneth Rothman: when a subject is exposed to a particular germ, say the tuberculosis bacillus, until the appearance of symptoms it is required that other elements accumulate in conjunction with the 
exposition; e.g., if the subject also develops nutritional impairments or immunodeficiency, we would have a minimally sufficient condition for which exposure to the bacillus is a necessary element. The latency time was already explained in the very conceptual framework of INUS conditions and this would also include positive elements, let us say, that the subject is perfectly nourished, in this case the latency period can stretch or even never get to the point of create the minimal sufficient conditions to the effect ${ }^{17}$. To move this discussion into the realm of neuropsychiatry, we can find an illuminating example in Alzheimer's disease: The accumulation of beta-amyloid, the tau protein phosphorylation and the neurocellular degeneration can form a minimally sufficient causal set, where the accumulation of beta-amyloid is a necessary element for the whole conjunction (Figure 2). Aging brings these same changes, with an increase at different rates in different subjects, so the long latency to the onset of cognitive symptoms is already included in the theoretical framework offered by the idea of INUS condition. This seems to be an advantage with respect to how Bradford Hill approached causality, because it is not necessary to resort to different models of causality (namely material and probabilistic models), but the argument is already conceptually linked to INUS conditions.

\section{Causal strength}

No concept is more precious to the epidemiologist than strength of association. Perhaps this is because of historical reasons, since it was the strength of the relationship between smoking and cancer that contributed to the development of the parameters defined by Hill. However, when analyzing the measure of the strength of association, Thygesen et al., taking into account the presence of positive and negative factors in conformity with the INUS condition theory, argued that the strength of a causal factor A is dependent upon the prevalence of its components $\mathrm{X}$ and $\mathrm{Y}$. What is consistent, according to them, with the idea that the effect of one factor depends on the prevalence of its components. Thus, if a negative Y component is sufficiently prevalent, from this we can conclude that A can be weak in relation to the effect, while in other conditions where $\mathrm{Y}$ is not as prevalent, the strength of A would become more apparent. Thus, the strength of an association is dependent upon the occurrence of the complementary factors, which we represented as $\mathrm{X}$ and $\mathrm{Y}^{2,18}$. This means that when using broader concepts to analyze the associations between events, we will also have to adjust the interpretation of some central concepts of epidemiology, so that it better represents the circumstances under consideration (Figure 3).

Furthermore, the idea of strength has little explanatory capacity. According to Rothman, although the risk factors can be characterized as strong or weak such characterization may not be made universally. To use another example given by him, in a society where most people consume a diet rich in phenylalanine the heritage of the PKU gene would be a strong risk factor for mental retardation. If, on the other hand, the population under analysis has high prevalence of the gene, but no one consumes a diet rich in that substance, then the inheritance of the gene would give a weak risk and diet would be a strong risk factor. That said, as important as the idea of risk factor can be for public health policies, it has little explanatory power on its own ${ }^{17}$.

Strength, therefore, is expressed dependably on its causal elements. The study of the relationship between smoking and lung cancer made the discussion easier by virtue of the particularly high tobacco carcinogenesis power (somewhat strong causal influence), but even there other elements are involved, i.e., the genes inherited, use of other drugs, diet, smoking intensity, exposure time, etc.

While the advantage of this kind of analysis is less obvious when it comes to infectious disease, for chronic disease, and particularly for psychiatric disorders, such a model can help to explain part of the difficulty in addressing the issue of etiology in psychiatry. Consider for example the case of schizophrenia, there is a multitude of factors participating in the causation of this disease ${ }^{11,19}$ and among them there is the abuse of marijuana as a teenager $(\mathrm{A})$, high paternal

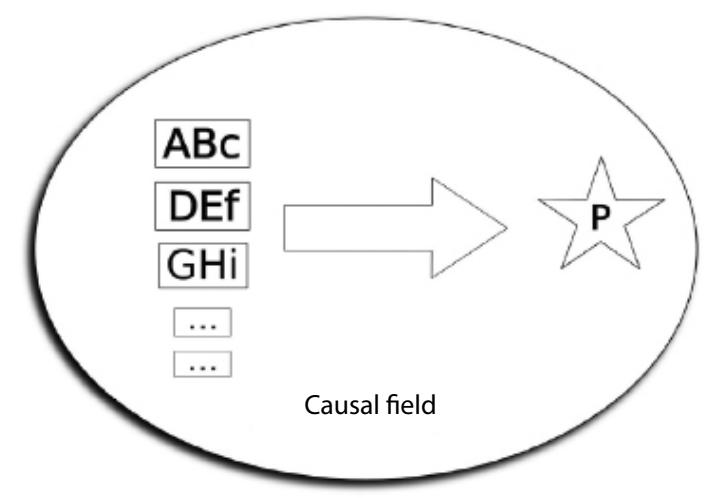

Figure 1. Visual representation of the analytical argument of an INUS condition acording to Mackie. In a given causal field, i.e., all the adjacent and redundant conditions related to the effect $(P)$, there are minimally sufficient conditions (here represented as $A B C$, $\mathrm{DEf}, \mathrm{GHi})$ formed by a conjunction of positive elements $(\mathrm{B}, \mathrm{E}, \mathrm{H}$; or for example the presence of inflammable material, oxygen etc.) and negative elements (cfi; or the absence of a proper sprinkler, etc.). An INUS condition occur when one of the elements is necessary for the entire conjunction (in the case when $A$ is necessary to the conjunction $A B c$, or when $D$ is necessary to $D E f$ or $G$ to $G H i)$, furthermore this conjunction is then necessary to the effect $(P)$. Each conjunct must not be limited by only three elements, Mackie allows for numerous elements to take place in the minimal sufficient condition, we only scaled down the conjunctions for the sake of clarity. In Mackie's example the short-circuit (A) is necessary to the conjunction formed by the other elements like the presence

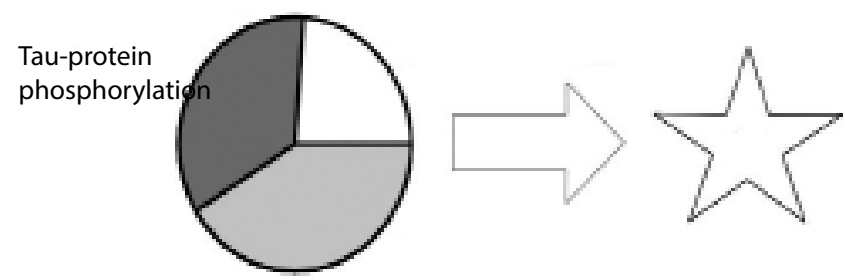

Beta-amyloid accumulation

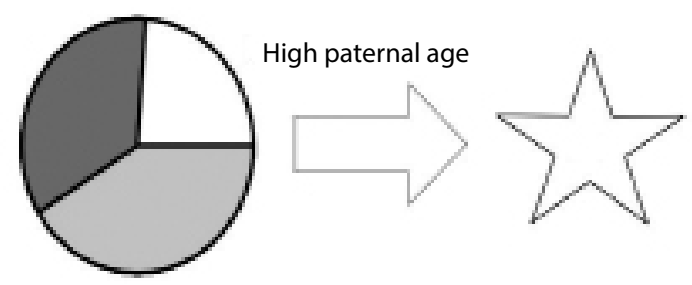

Figure 2. Taking the example of Alzheimer's disease (AD): the accumulation of beta-amyloid, tau phosphorylation and neurocellular degeneration can form a minimally sufficient condition and hence an INUS condition (a). A second example (b) can be drawn from schizophrenia (Ez), a disease for which we know numerous elements participating in the causal "recipe", among them there is the marijuana abuse, elevated paternal age , urbanicity; an INUS condition is a conjunction where those elements are involved 


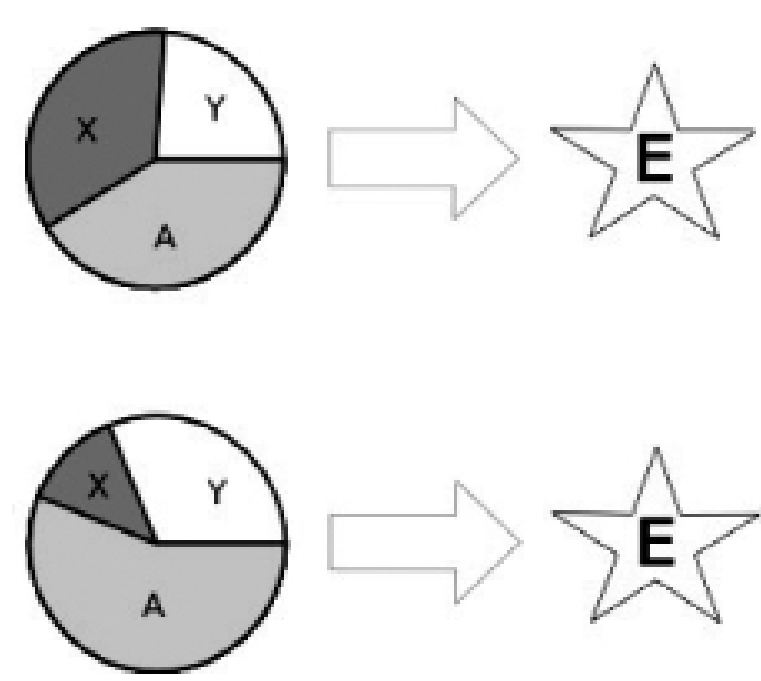

Figure 3. Taking two different experiments, the causal strength can be similar depending on the participation of each one of its components. In both cases the same effect $E$ is produced ${ }^{26}$.

age $(\mathrm{X})$, migration $(\mathrm{Y})$, urbanicity $(\mathrm{Z})$. An INUS condition may be a combination in which these elements are involved and that the abuse of marijuana, in those circumstances, is necessary for the effect (schizophrenia) (this example of conjunction has no actual bearing on reality; at least it has not been tested as such). Note that this form of analysis requires significant modification of the statistical analysis, changing the focus from biunivocal relations to an idea of cause as multiple sets of elements (not all of the sets are known, and no set is, up to now, entirely known).

If we take the INUS model into consideration, then Hill's criteria require revision. This does not mean that already established and important concepts such as biological gradient, experimental evidence or strength are undermined, but one should realize that statistical operators arising from these ideas (FR, odds ratio, $p$ ) should be interpreted with great caution. Some lower level logical dependencies occur on the analysis of causes and these relations sometimes cannot be captured by statistical methods. However, we are dependent on the application of statistical principles in order to make inferential reasoning between two events in medicine. We therefore suggest that the seminal proposal of Bradford Hill can be refined in the light of Mackie's concepts of causal field and necessity-in-the-circumstances, incorporating into probabilistic analysis notions such as weak causal influences, INUS conditions, negative-component causes (i.e., preventive for the effect) and sets of associated factors (whose elements are not always known).

Furthermore, it is important to acknowledge that this philosophically informed analysis only addressed the contributions of Bradford Hill and Mackie. In this article the expression "complex causal networks" was used simply to indicate that numerous elements played a role in the production of a given effect. Of course there is a lot more to be presented about the study of complex causation, but that was beyond our reach here. Let us shortly mention that other authors developed theories using concepts from other fields like econometrics and artificial intelligence to tackle the same problem from different perspectives, resulting in numerous publications in the scientific literature. For example, network modeling was used to approach the relation between psychopathological features in the diagnostic categories on DSM IV ${ }^{20}$ and showed that from a network analysis perspective it is unlikely that we will be able to narrow down diagnostic categories based on aetiology. Also, studies using techniques derived from Granger causality test (named after the 2003 Nobel winner in economics) were applied in neuroimaging to track the connection between neuron circuits ${ }^{21}$, and Bayes theorem have been used to analyze complex causation nets ${ }^{22}$ and as a basis to a theory of perception through the idea of prediction error minimization ${ }^{23-25}$.

\section{Conclusion}

Associations do not necessarily imply causal relations, even though there is a long history of attempts to equalize the two concepts. Bradford Hill's work is at the forefront of its time and paved the way for successful innovations in the study of chronic diseases. Models such as the one proposed by JL Mackie can complement the work of Hill, establishing a stronger theoretical basis for medical statistics. This approximation with analytic philosophy can contribute to better understandings of what statistics may or may not offer through concepts such as strength, consistency, specificity and plausibility. Despite this aspect of theoretical clarification, such models offer gains for psychiatry especially through the explanatory power implicit in INUS conditions. Causality is an important topic in psychiatry; after all, establishing etiology also means opening the horizon for the possibility of intervention and treatment. Robust advances require rigorous theoretical basis and it is precisely here where philosophical insights can contribute to the sciences. This is why we consider it important to bring together authors such as Bradford Hill and Mackie, incorporating thus this dimension of multi-causality into statistical analysis.

\section{References}

1. Phillips CV, Goodman KJ. The missed lessons of Sir Austin Bradford Hill. Epidemiol Perspect Innov. 2004;1(1):3.

2. Thygesen LC, Andersen GS, Andersen H. A philosophical analysis of the Hill criteria. J Epidemiol Community Health. 2005;59(6):512-6.

3. Hill AB. The environment and disease: association or causation. Proc R Soc Med. 1965;58:295-300.

4. Doll R, Hill A. The mortality of doctors in relation to their smoking habits. BMJ. 1954;328:1529-33.

5. Susser M. What is a cause and how do we know one? A grammar for pragmatic epidemiology. Am J Epidemiol. 1991;133(7):635-48.

6. Mackie JL. The concept of causation - Conditional analyses. In: Mackie JL. The cement of the universe: a study of causation. New York: Oxford University Press; 1980. p. 29.

7. Mackie JL. Causes and conditions. In: Kim J, Sosa E, editors. Metaphysics: an anthology. Oxford: Blackwell; 1999. p. 413-27.

8. Hume D. Tratado da natureza humana. $2^{\text {nd }}$ ed. Editor: Danowski D. São Paulo: Editora Unesp; 2000.

9. Berrios GE. Historical development of ideas about psychiatric aetiology In: Gelder M, Andreasen N, Lopez-Ibor J, Geddes J, editors. New Oxford Textbook of Psychiatry. New York: Oxford University Press; 2009.

10. Mayr E. Cause and effect in biology. Science. 1961;134:1501-6.

11. Castro-de-Araujo LFS. "Weak" causes and complex causal nets in psychiatry. Rev Latinoam Psicopatol Fundam. 2014;17(1):14-27.

12. Kievit R, Frankenhuis W. Simpson's paradox in psychological science: a practical guide. Front Psychol. 2013;4:1-14.

13. Russo F, Williamson J. Generic versus single-case causality: the case of autopsy. Eur J Philos Sci. 2010:1-22.

14. Cartwright N. Causal laws and effective strategies. Noûs. 1979;13(4):41937.

15. Mackie JL. The cement of the universe: a study of causation. paperback. Editor: Cohen LJ. New York: Oxford University Press; 1980.

16. Esserman LJ, Thompson IM Jr, Reid B. Overdiagnosis and overtreatment in cancer an opportunity for improvement. JAMA. 2013;310(8):797-8.

17. Rothman KJ. Causes. J Epidemiol. 1976;141(2):587-92.

18. Luiz RR, Struchiner CJ. Inferência causal em epidemiologia: o modelo de respostas potenciais. $1^{\text {st }}$ ed. Rio de Janeiro: Fiocruz; 2002.

19. Tandon R, Keshavan MS, Nasrallah HA. Schizophrenia, "just the facts" what we know in 2008. 2. Epidemiology and etiology. Schizophr Res. 2008;102(1-3):1-18.

20. Borsboom D, Cramer AOJ, Schmittmann VD, Epskamp S, Waldorp LJ. The small world of psychopathology. PLoS One. 2011;6(11):e27407. 
21. Friston K, Moran R, Seth AK. Analysing connectivity with Granger causality and dynamic causal modelling. Curr Opin Neurobiol. 2013;23:172-8.

22. Russo F, Williamson J. Interpreting probability in causal models for cancer. In: Russo F, Williamson J, editors. Causality and probability in the sciences, Texts in Philosophy (5). London, UK: College Publications; 2007. p. 217-42.
23. Frith $\mathrm{C}$, Friston K. False perceptions and false beliefs: understanding schizophrenia. Neurosci Hum Pers New Perspect Hum Act. 2013;1-15.

24. Howy J. The predictive mind. $1^{\text {st }}$ ed. Oxford: OUP; 2013.

25. Moore JW, Obhi SS. Intentional binding and the sense of agency: a review. Conscious Cogn. 2012;21(1):546-61. 